\title{
200 anos de Dom Bosco: a Pedagogia Salesiana, a universidade para a maioridade e a primazia da dignidade da pessoa humana
}

200 years of Don Bosco: the Salesian Pedagogy, the university for the majority and the primacy of the dignity of the human person 200 años de Don Bosco: la Pedagogía Salesiana, la universidad para la mayoría y la primacía de la dignidad humana

Daner Hornich ${ }^{1}$

Fabio Camilo Biscalchin ${ }^{1}$

DOI: http://dx.doi.org/10.20435/serie-estudos.v23i48.1118

\begin{abstract}
Resumo: Neste artigo, o nosso objeto de estudo é a experiência educativa de Dom Bosco (18151888) e os seus desdobramentos na formação educacional juvenil universitária salesiana, assim como o papel significativo na universidade católica como possibilidade contrária à mercantilização do ensino que reduz a dignidade da pessoa humana. Nesse sentido, promovemos um diálogo entre Dom Bosco, Kant e Schelling para pensar a pedagogia salesiana como educação integral, a universidade e a primazia da dignidade humana no itinerário da formação dos jovens universitários nas instituições de matizes cristãs católicas, como contraponto ao processo de vulgarização mercantilista do ensino e aprendizagem no Ensino Superior que decreta a falência do pensamento em nome de um antiacademicismo apressado e preguiçoso, que não educa para a autonomia, para liberdade, para o sentido da vida e para o pensamento crítico e alargado do cidadão esclarecido e comprometido com a vida digna da pessoa humana na comunidade e na vida pública, o que visa ao bem comum de todos na sociedade e no Estado.
\end{abstract}

Palavras-chave: Dom Bosco; Kant; Schelling; universidade.

\begin{abstract}
In this article, our object of study is the educational experience of Don Bosco (18151888) and its developments in the Salesian university education as well the significant role in the Catholic university as a possibility contrary to the commodification of education that reduces the dignity of the person human. In this sense, we promote a dialogue between Don Bosco, Kant and Schelling in order to think of Salesian pedagogy as integral education, the university and the
\end{abstract}

${ }^{1}$ Centro Universitário Salesiano de São Paulo, Americana, São Paulo, Brasil. 
primacy of human dignity in the itinerary of the formation of young university students in Catholic Christian institutions, as a counterpoint to the process of popularization mercantilist of teaching and learning in Higher Education that decrees the bankruptcy of thought in the name of a rushed and lazy anti-academy that does not educate for autonomy, for freedom, for the meaning of life and for the critical and extended thinking of the enlightened and committed citizen with the dignified life of the human person in the community and in public life, wthat aims at the common good of all in society and in the State.

Keywords: Don Bosco; Kant; Schelling; university.

Resumen: En este artículo, nuestro objeto de estudio es la experiencia educativa de Don Bosco (1815-1888) y sus desdoblamientos en la formación educativa juvenil universitaria salesiana y el papel significativo en la universidad católica como posibilidad contraria a la mercantilización de la enseñanza que reduce la dignidad de la persona humana. En este sentido, promovemos un diálogo entre Don Bosco, Kant y Schelling para pensar la pedagogía salesiana como educación integral, la universidad y la primacía de la dignidad humana en el itinerario de la formación de los jóvenes universitarios en las instituciones de matices cristianos católicos, como contrapunto al proceso de vulgarización de la enseñanza y el aprendizaje en la Enseñanza Superior que decreta la quiebra del pensamiento en nombre de un antiacademicismo apresurado y perezoso que no educa para la autonomía, para la libertad, para el sentido de la vida y para el pensamiento crítico y ampliado del ciudadano esclarecido y comprometido con la vida digna de la persona humana en la comunidad y en la vida pública que apunta al bien común de todos en la sociedad y en el Estado.

Palabras clave: Don Bosco; Kant; Schelling; universidad.

\section{INTRODUÇÃO}

O nosso objeto de estudo é a experiência educativa de Dom Bosco (18151888) e os seus desdobramentos na formação educacional juvenil universitária salesiana, assim como o papel significativo na universidade católica como possibilidade contrária à mercantilização do ensino que reduz a dignidade da pessoa humana. Na primeira parte do artigo, contextualizamos a presença Dom Bosco em meio às ebulições e transformação da sociedade do seu tempo. Na segunda parte, localizamos a respostas de Dom Bosco aos problemas do seu tempo, com a proposta de uma pedagogia salesiana, que se configura na formação integral. Na terceira parte, propomos um diálogo entre a universidade para a maioridade num diálogo aberto com a pedagogia salesiana. Na quarta e última parte do artigo, promovemos um debate entre Kant e Dom Bosco, mas a partir de um texto de Schelling para desenvolvermos uma breve discussão sobre a primazia da dignidade da pessoa humana em meio ao método e estudo acadêmico. 


\section{TEMPO DE DOM BOSCO:A SOCIEDADE EM EBULIÇÃO ETRANSFORMAÇÃO}

A experiência de padre João Bosco na Itália está dentro do contexto histórico do processo de industrialização na Europa e, de forma específica, na cidade de Turim. Contudo a situação das pessoas que trabalhavam no processo industrial era degradante e desumanizante.

Conforme escreveu Friedrich Engels (1820-1895) sobre "A situação da classe trabalhadora na Inglaterra" em 1845, eram "milhões de despossuídos que consomem hoje o que ganharam ontem" (ENGELS, 2010, p. 60). Contudo podemos constatar que a vida da classe trabalhadora em Turim não era muito diferente da inglesa, pois as massas de jovens na "Itália" em processo de unificação (começa em 1814, no Congresso de Viena, até 1929 - ano da unificação), percorriam as cidades em processo de industrialização em busca de uma promessa de futuro material melhor. Mas o futuro melhor beneficiou os "donos da indústria", e não a classe trabalhadora.

João Bosco viveu em pleno desenvolvimento do capitalismo industrial na Europa; segundo análise de Karl Marx (1818-1883) sobre a gênese do capitalismo no "Manifesto Comunista", podemos compreender que:

[...] os mercados ampliavam-se cada vez mais, a procura por mercadorias continuava a aumentar. A própria manufatura tornou-se insuficiente; então, o vapor e maquinaria revolucionaram a produção industrial. A grande indústria moderna suplantou a manufatura; a média burguesia manufatureira cedeu lugar aos milionários da indústria, aos chefes de verdadeiros exércitos industriais, aos burgueses modernos. (MARX; ENGELS, 2010, p. 41).

Seguindo a análise de Marx no manifesto comunista, podemos constatar que os empregadores inescrupulosos se enriqueceram com o trabalho alheio e, ao mesmo tempo, criaram uma massa de trabalhadores marginalizados na vida social, pois com tal desenvolvimento da "burguesia capitalista":

[...], desenvolveu-se também o proletariado, a classe dos operários modernos, os quais só vivem enquanto têm trabalho e só têm trabalho enquanto seu trabalho aumenta o capital. Esses operários constrangidos a vender-se a retalho, são mercadoria, artigo de comércio como qualquer outro; em consequência, estão sujeitos a todas as vicissitudes da concorrência, a toda as flutuações do mercado. (MARX; ENGELS, 2010, p. 46).

O cenário da classe trabalhadora analisado por Marx na gênese do capitalismo industrial, na perspectiva do Manifesto Comunista, nos possibilita construir 
um dos contextos dos tempos de Dom Bosco, quando o "capitalismo triunfante" não resolveu os problemas relacionados ao campo social, político e econômico que se preocupava com a vida e a dignidade da pessoa humana (Cf. ZIMNIAK, 2013, p. 45), mas tratou de sugar a vida das pessoas pelo processo do capital, como salientou Marx no livro O Capital, pois:

[...] o capital tem um único impulso vital, o impulso de se autovalorizar, de criar mais-valor, de absorver, com sua parte constante, que são os meios de produção, a maior quantia possível de mais-trabalho. O capital é trabalho morto, que, como um vampiro, vive apenas de sucção de trabalho vivo, e vive tanto mais quanto mais trabalho vivo suga. O tempo durante o qual o trabalhador trabalha é o tempo durante o qual o capitalista consome a força de trabalho que comprou do trabalhador. Se este consome seu tempo disponível para si mesmo, ele furta o capitalista. (MARX, 2013, p. 307).

O tempo de Dom Bosco é o tempo do Capital e dos seus processos avassaladores e incontroláveis de transformações, revoluções e ebulições ${ }^{2}$ sobre a vida da classe trabalhadora e da juventude, que compunha a grande massa de operários nas fábricas e no centro urbano de Turim, que se modernizava no processo industrial. Contudo o tempo de Dom Bosco é o tempo da "Teoria da Evolução" de Charles Darwin (1809-1882), que mudou no homem a sua "visão da natureza" e o seu modo de perceber e conceber a sua inserção na natureza e no mundo 3 . Também não podemos esquecer de destacar é que a Europa passava por processo de secularização e laicização, isto é, a forma de governo muda a forma de ver o mundo e agir sobre o Estado, pois a religião começa perder o seu espaço público

\footnotetext{
2 "Tudo o que era sólido e estável se desmancha no ar, tudo o que era sagrado é profano e os homens são obrigados finalmente a encerrar sem ilusões a sua posição social e as suas relações com os outros homens" (MARX; ENGELS, 2010, p. 43).

3 "Com efeito, tem-se a nítida impressão de que Darwin tinha consciência do terremoto que sua teoria provocaria, não só na Inglaterra puritana, mas também em outros lugares do Ocidente cristão. Tudo isso após um século em que a Revolução Francesa e a Revolução Industrial prenunciavam abalos nas estruturas do poder político e no pensamento tradicional sacudido pelo 'ideário iluminista' - uma nova racionalidade, uma sociedade civil, um Estado laico e democrático, instituições públicas laicas e direitos humanos. Uma pauta que permitia vislumbrar no horizonte a possibilidade de poder viver com liberdade de ideias e tolerância de confissões religiosas. Ora, a publicação da obra de Darwin revelava que o efetivo foco das reações contrárias que ela provocou, e continua provocando dois séculos depois, é a resistência das ideologias fechadas, políticas e religiosas, hoje denominadas 'fundamentalismos', à ideia de liberdade de pensamento. É a questão inescapável da relação - quase impossível - entre ciência e fé" (PINO, 2009, p. 801).
} 
de ação sobre o modo de governo dos Estados e se refugia para os "espaços da intimidade" 4 .

Pietro Braido, ao contextualizar a figura de Dom Bosco em meio da ruptura entre a Igreja e o Estado e da revolução política pela qual passava a Europa, argumenta que:

Tendo crescido em clima de restauração civil e religiosa, Dom Bosco não podia deixar de ser tocado pela revolução política dos anos 1847-1865, sem compreender-Ihes de modo pleno o significado profundamente cultural. Tendo-se afirmada com o suceder-se de agrupamentos politicamente mesclado, a revolução levava à definitiva prevalência das forças liberais que mantiveram o poder até os inícios do terceiro decênio do século XX. Associaram-se a ela a laicização progressiva do Estado, a secularização rasteira do tecido social, a marginalização acentuada dos católicos em relação à vida política, antes obrigada e desejada. Dom Bosco, em vários escritos, sublinha esses fenômenos, segundo os contextos, em relação às vicissitudes da Igreja turinense e aos próprios oratórios, ou ao problema das vocações eclesiástica, ou, em referência mais explicita às leis subversivas de 1855, a seu modo de conceber e gerir a Sociedade de São Francisco de Sales, que talvez já esteja prefigurado de algum modo naquele ano. (BRAIDO, 2008a, p. 35).

Em meio a esses processos todos de transformações, questionamentos e inquietações no campo social, político, cultural, econômico, religioso e científico, quais foram as respostas de Dom Bosco ao novo que surgia e mudava a vida dos jovens do seu tempo, que perambulavam pelas ruas de Turim em busca de trabalho e um sentido para viver em meio as mudanças que transformavam a sua vida e seu entorno? A resposta mais significativa para a juventude à margem da sociedade turinense foi a criação, aos moldes modernos, da Sociedade de São Francisco de Sales, pois tal empreendimento demonstrava o quanto Dom Bosco tinha ciência da delinquência, da vida insuportável nas casas correcionais e da vida miserável que os jovens viviam para se sustentarem e, ao mesmo tempo, levarem uma vida com dignidade. Segundo, Pietro Braido (2008a, p. 33), era:

[...] notável o crescimento da população na capital subalpina nos anos 1814-1848- cerca de 62\% - , graças sobretudo à imigração, com 35\% desse crescimento, sem diferenças entre homens e mulheres. Não se tratava de

\footnotetext{
${ }^{4}$ Sobre esse assunto consultar a obra da Hannah Arendt - A Condição Humana (2010) na parte em que se discute a temática: "O social e o privado", nas páginas 83-90.
} 
mão-de-obra qualificada, mas de adidos temporários à construção civil ou aos transportes, artesãos, vendedores ambulantes, domésticos, massas de camponeses expulsos da miséria dos campos e dos salários de fome, entregues em grande parte a mendicâncias. Essa é, na cidade, justamente a mais vistosa protagonista do mal-estar social, particularmente nos arrabaldes Pó e Dora, tangível no miserável bairro do Moschino. Degenerava não raramente nos frutos, nas agressões e na prostituição, também de menores. Aqueles que caíam nas mãos das autoridades abriram-se "os lugares de piedade e do castigo, os asilos de mortalidade e as prisões.

Dom Bosco, tendo ciência de todas as ebulições pelas quais passava a Europa e, de modo especial, a Itália em processo de unificação, do crescimento populacional, miséria, desigualdade social e de um desequilibrado atraso e progresso industrial, como homem de ação, propõe uma saída educativa fundada na formação integral aos jovens de Turim, para não mergulharem suas vidas na delinquência e na exploração social, política e econômica.

\section{A RESPOSTA DE DOM BOSCO: A PEDAGOGIA SALESIANA COMO FORMAÇÃO INTEGRAL}

A resposta de Dom Bosco aos problemas do seu tempo em relação ao processo da industrialização e os seus desdobramentos de exploração e marginalização dos jovens, foi um empreendimento educacional, que fundava e organizava a ação educativa na formação dos seus jovens para uma vida material melhor por meio de uma formação integral, pois Dom Bosco sabia que, sem o mínimo de sustentação para vida digna, não era possível nem uma vida espiritual, nem uma perspectiva religiosa de vida. Nesse sentido, Dom Bosco propõe uma inovadora forma de educar os jovens que se convencionou chamar Sistema Preventivo, o qual, como argumenta Stanislaw Zimniak (2013, p. 46):

[...] é fruto de um longo caminho, vivido e experimentado em vários momentos, antes de chegar a uma formulação mais precisa e codificada em vários escritos. Quando se trata do Sistema Preventivo de Dom Bosco não é possível limitar-se, então, ao famoso texto O Sistema Preventivo na educação da Juventude. Esse texto foi publicado pela primeira vez como apêndice ao opúsculo sobre a inauguração do Patronato de S. Pedro, de Nice (França), em agosto de 1877, edição preparada pelo próprio Dom Bosco. Sua intenção era expor ao público as bases fundamentais do Sistema educativo experimentado e praticado nos seus institutos turinenses. 
O Sistema Preventivo de Dom Bosco é filho dos tempos modernos e embrião dos processos "científicos experimentais" e educacionais da modernidade 5 , a proposta de Dom Bosco não é um sistema fechado, mas um processo educativo experimentado na cotidianidade das obras salesianas. Nossa proposta não é fixar-se ou deter-se no "Sistema Preventivo Educativo na Educação da Juventude", mas localizar no "Sonho dos Nove Anos", o coração do Sistema Preventivo que é a salesianidade em seus desdobramentos para a formação da educação integral6. Não vamos relatar, estudar e interpretar todo "O Sonho dos Nove Anos" de Dom Bosco (2005) como se encontra nas Memórias do Oratório (1815-1855). Nosso propósito é demonstrar algumas nuances do sonho dos nove anos e provocar um debate em torno da salesianidade como força integradora do Sistema Preventivo na formação integral dos jovens.

Dom Bosco narra da seguinte forma o sonho nas Memórias do Oratório:

Nessa idade tive um sonho que me ficou profundamente impresso na mente por toda a vida. Pareceu-me estar perto de casa, numa área bastante espaçosa, onde uma multidão de meninos estava a brincar. Alguns riam, outros divertiam-se, não poucos blasfemavam. Ao ouvir as blasfêmias, lancei-me de pronto no meio deles, tentando com socos e palavras, fazê-los calar. Nesse momento apareceu um homem venerado, de aspecto varonil, nobremente vestido. Um manto branco cobria-Ihe o corpo; seu rosto, porém, era tão luminoso que eu não conseguia fitá-lo. Chamou-me pelo nome e mandou que eu me pusesse à frente daqueles meninos, acrescentando estas palavras:- Não é com pancadas, mas com mansidão e caridade que deverás ganhar esses teus amigos. Põe-te imediatamente a instruí-los sobre a fealdade do pecado e a preciosidade da virtude. Confuso e assustado, repliquei que eu era um menino pobre e ignorante, incapaz de Ihes falar de religião. Senão quando

\footnotetext{
5 Sobre esse assunto consultar a obra de Jean-Jacques Rousseau - "Emílio ou Da educação" que é fruto de "reflexões e observações, sem ordem e quase sem sequência, foi iniciada para agradar a uma boa mãe que sabe pensar" (ROUSSEAU, 2004, p. 3) para verificar o estilo literário destes escritos na modernidade.

6 "O coração da salesianidade são o sistema preventivo, as memórias e as cartas - Carta de Roma (carta aos jovens - esquecida até 1920), três cartas missionárias aos padres João Cagliero, Tiago Costamagna e Domingos Tomatis, todas escritas em 1885. As cartas de Dom Bosco são o patrimônio da cultura salesiana para compreender o sistema educativo de Dom Bosco. Por isso, não é possível estudar o seu pensamento pedagógico sem ter presente esta produção articulada. São Textos que, embora em forma assistemática, oferecem um quadro rico, variado do ponto de vista literário e diferenciado quanto ao valor do pensamento pedagógico" (ZIMNIAK, 2013, p. 48).
} 
aqueles meninos, parando de brigar, de gritar e blasfemar, juntaram-se ao redor do personagem que estava a falar. Quase em saber o que dizer, acrescentei:- Quem sois vós que me ordenais coisas impossíveis? - Justamente porque te parecem impossíveis deves torná-las possíveis com a obediência e a aquisição da ciência. - Onde, com que meios poderei adquirir a ciência? Eu te darei a mestra, sob cuja orientação poderás tornar-te sábio, e sem a qual toda sabedoria se converte em estultice. - Mas quem sois vós que assim falais? - Sou o filho daquela que tua mãe te ensinou a saudar três vezes ao dia. - Minha mãe diz que sem sua licença não devo estar com gente que não conheço; dize-me, pois, vosso nome. Pergunta-o a minha mãe. Nesse momento, vi a seu lado uma senhora de aspecto majestoso, vestida de um manto todo resplandecente, como se cada uma de suas partes fosse fulgidíssima estrela. Parecendo-me cada vez mais confuso em minhas perguntas e respostas, acenou para que me aproximasse e, tomando-me com bondade pela mão, disse:- Olha. Vi então que todos os meninos haviam fugido e, em lugar deles estavam uma multidão de cabritos, cães, gatos, ursos e outros animais. - Eis o teu campo, onde deves trabalhar. Torna-te humilde, forte, robusto ${ }^{7}$; o que agora vês acontecer a esses animais, deves fazê-lo aos teus filhos. Tornei então a olhar, e, em vez de animais ferozes, aparecerem mansos cordeirinhos que, saltitando e balindo, corriam ao redor daquele homem e daquela senhora, como a fazer-Ihes festa. Neste ponto, sempre no sonho, desatei a chorar, e pedi que falassem de maneira que pudesse compreender, porque não sabia o que significava tudo aquilo. A senhora descansou a mão em minha cabeça, dizendo:- A seu tempo tudo compreenderás. Após essas palavras, um ruído qualquer me acordou, e tudo desapareceu. Fiquei transtornado. Parecia-me ter as mãos doloridas pelos socos que deferira e doer-me o rosto pelos tapas recebidos; além disso, aquele personagem, a senhora, as coisas ditas e ouvidas de tal modo me encheram a cabeça que, naquela noite, não pude mais conciliar o sono. (FERREIRA, 2010, p. 18-9).

Nos sonhos dos noves anos temos nuances centrais para fundamentar a educação salesiana e as bases que dão suporte para o Sistema Preventivo, como formação integral da educação cristã e salesiana, pois o "o sonho que ficou impresso na mente" de Dom Bosco por toda a sua vida retrata o imaginário religioso, cultural, social e político do seu tempo. Como diz Pietro Braido (2008a, p. 92-3):

O catolicismo praticante transforma-se, no século XIX, com vigor renovado, em militante, caritativo e social. Retornava o ora et labora, com interação entre as duas realidades. Tratava-se do esforço para "a maior gloria de Deus

\footnotetext{
7 “Inicialmente, Dom Bosco havia escrito: 'torna-te sábio, forte, robusto'” (FERREIRA, 2010, p. 19).
} 
e a salvação das almas", que estava no coração dos Exercícios de Santo Inácio. Era "a verdadeira e sólida piedade" da qual escrevia Pierre Collot (1672-1741) a propósito da doutrina espiritual de São Francisco de Sales. Era a síntese de amor afetivo e efetivo já proclamado com as palavras e o exemplo por São Francisco de Sales e São Vicente de Paulo. No ambiente piemontês, junto com São Felipe Néri, eles eram vistos como santos da caridade cativante, expressa no zelo profuso para atrair as almas a Cristo e reconquistá-las de heresia para a Igreja. Também nas novas congregações religiosas de vida ativa, a missão parece muitas vezes dominante sobre a congregação, embora sendo esta a fonte, tornando-se caridade operativa, sobretudo no campo da assistência, da educação e da tensão missionária: "caritativos porque religioso".

Dom Bosco é um padre militante e um comunicador do catolicismo que se expressa em ações caritativa e social; por meio dos seus sonhos, interpreta o imaginário religioso, político, social e cultural da sociedade da sua época. Os sonhos de Dom Bosco são um reflexo invertido da sociedade. A sociedade em que Dom Bosco viveu era uma sociedade em ebulição e passava por muitas transformações como salientamos. A violência instaurada contra a Igreja pelo processo de laicização e da unificação da Itália aparece no sonho como blasfêmia dos poucos, pois não foi a multidão (meninos estavam a brincar) como um todo que participa do processo de unificação, mas a elite (os poucos) educada da sociedade turinense, que se insurge contra os mandos da Igreja. Dom Bosco percebe que a violência gera violência e que não é possível agir com violência contra aqueles que rompem com a ordem estabelecida. A ação contra os blasfemadores é a caridade e a mansidão (paz), o exemplo a ser seguido é do mestre Jesus Cristo. E, segundo a concepção dos tempos de Dom Bosco.

[...] Não era suficiente o esforço humano. Nada era possível sem ajuda da graça. Ela era garantida pelo remédio universal da frequência aos sacramentos - confissão e comunhão -, recebidos com a devida disposição e num intervalo adequado aos objetivos professados. Associava-se o nome de Deus aos sentidos do temor, que não era somente medo dos castigos, mas principalmente veneração, respeito, temor de frágeis criaturas e de filhos confiantes. As sentenças bíblicas eram axiomas: Initium sapientiae timor Domini e Sapientia nos introibit in animan malevolam et non habitat in corpore súbdito peccatis. O jovem retamente temeroso de Deus agia conforme sua boa consciência, e não por medo dos castigos humanos ou da expulsão. (BRAIDO, 2008b, p. 217). 
Numa atitude pessoal, Jesus chama Dom Bosco pelo nome e the proporciona uma missão - educação daqueles blasfemadores, por meio da instrução sobre o que causa o pecado daqueles homens, mulheres e jovens daquela época e, como proposta, oferece a possibilidade de uma educação virtuosa, carregada como sabemos pela pedagogia espiritual salesiana de Dom Bosco, que

[...] era dirigida à juventude pobre e abandonada, geralmente se encontrava diante de jovens necessitados - segundo ele - de uma "reforma moral" mais empenhativa. Estava orientada, ante de tudo, à recuperação, à defesa, à conversação e aos desenvolvimentos da vida da graça, considerada como o máximo bem do jovem cristão, sinônimo de santidade substancial, garantida de vida feliz no tempo e além do tempo. A guerra ao pecado, em suas variadas formas, era fundamental, sendo relevante a relativa ao campo sexual, que poderia tornar-se matriz de uma vida infeliz e, mais tragicamente, a antecâmera da temida condenação eterna. (BRAIDO, 2008b, p. 546).

Ciente da proposta ousada de Jesus sobre a educação salesiana para a virtude do cidadão e cristão do seu tempo, Dom Bosco coloca-se na posição de vítima, isto é, como aquele que não tem capacidade para tal empreendimento, pois é um garoto pobre, ignorante e incapaz de falar de religião. Contudo Jesus, no sonho, mostra o caminho para aquilo que parece impossível, mas não é. E a primeira proposta é escutar (obedecer) o clamor do seu tempo, prestar atenção no barulho estridente da modernidade do seu tempo e aprender com a audição as coisas que acontecem, e não ficar na tagarelice ${ }^{8}$; em síntese, escutar a palavra do mestre com a sabedoria de Deus e agir com caridade. A segunda proposta de Jesus é adquirir ciência - e para isso é preciso estudar e se esforçar o máximo para conhecê-la, ou seja, não tem moleza e as coisas não caem do céu, mesmo com a graça de Deus, pois adquirir ciência é se fundamentar com afinco nos clássicos da literatura latina e cristã (Cf. BRAIDO, 2008b, p. 556). Também é preciso razão (retórica e lógica) para alcançar a virtude para entender e agir diante dos acontecimentos do seu tempo. Para que tal empreendimento ocorresse, "Dom Bosco exortava os professores mais apreciados e capazes a qualificar-se com preparação de textos escolares, comentários de autores latinos, edições de textos clássicos italianos, dicionários" (BRAIDO, 2008b, p. 554).

8 "...os tagarelas não ouvem ninguém, já que estão sempre falando. Eis o primeiro mal contido na incapacidade de se calar: a incapacidade de ouvir" (PLUTARCO, 2008, p. 11). 
Mas, quem será a pedagoga de Dom Bosco? A condutora de Dom Bosco é Maria, Mãe de Deus, que é a "meta esperada do jovem cristão que tinha Jesus como amigo e, como mãe, a virgem Maria" (BRAIDO, 2008b, p. 547). Enfim, Dom Bosco deverá tornar-se humilde, forte e robusto para aqueles homens, mulheres, jovens - blasfemos, que mais pareciam bestas feras para que eles se tornem pessoas humanas, filhos de Deus na sociedade do seu tempo e dos tempos vindouros. Com isso, argumentamos com Stanislaw Zimniak que a proposta de Dom Bosco é uma preocupação fundante entre a felicidade do bem eterno e terreno numa relação horizontal e vertical - espiritualidade interior que se externalizará nas ações da vida (Cf. ZIMNIAK, 2013, p. 46). E, sendo assim, entendemos que o fundamento do Sistema Preventivo é a formação integral das promoções e das potencialidades cognoscitivas e espirituais das gerações presentes e futuras.

Dentro desse quadro referencial, entendemos que o papel do educar salesiano é insubstituível como agente educador da comunidade, pois:

[...] no sistema preventivo - como afirma Braido - toda a metodologia preventiva é entregue ao educador (superior/diretor coadjuvado pelos colaboradores). No sistema repressivo, a responsabilidade executiva é como que toda do aluno: o diretor/educador exerce, além da tarefa de vigilância, sobretudo o poder judiciário-punitivo. No Sistema Preventivo, ao contrário, o educador é o protagonista absoluto, detentor da plenitude dos poderes executivo, judiciário, punitivo, enquanto o aluno é chamado a uma essencial execução cooperativa, coprotagonista subordinada. (ZIMNIAK, 2013, p. 51).

No Sistema Preventivo, o educador salesiano ${ }^{9}$ é autoridade no sentido romano da palavra, pois autoridade é aquela que acrescenta algo na vida das pessoas $^{10}$. E, como tal promove o bem dos seus alunos, por meio da disciplina e dos

9 "O sistema preventivo de Dom Bosco exige um educador maduro, humanamente e na fé confirmada com obras de caridade. Para Braido, trata-se uma pessoa equilibrada e integrada, capaz de viver generosamente disponível à sociabilidade, sensível às necessidades dos outros e aos problemas da vida associada em todos os níveis, local e planetário; uma pessoa extremamente relacionada, de modo privilegiado diante dos jovens, sobretudo se 'pobres e abandonados'. Homem de grande controle interior e exterior, temperante e prudente, ele ama o contato participativo com as necessidades dos jovens e sabe promover sabiamente a solidariedade de colaboradores, apoiadores, benfeitores'” (ZIMNIAK, 2013, p. 52-3).

${ }^{10}$ Estamos vivendo uma crise de autoridade nas sociedades modernas e ditas pós-modernas como um todo, e o sistema educacional é atingido em cheio, basta analisar as universidades que propõem a substituição do protagonismo do professor em sala de aula para o protagonismo 
estudos, numa linguagem do próprio Sistema Preventivo - os alunos aprendem os seus deveres com razão, amabilidade e religião num crescimento contínuo de "amadurecimento completo e integral" (ZIMNIAK, 2013, p. 52 e 56), isto é, de uma passagem da menoridade para a maioridade com alegria e coragem de saber ousar - pensar, projetar, sonhar e construir um algo novo para o "mundo da vida" nas sociedades contemporâneas (PAPA FRANCISCO, 2015).

\section{UNIVERSIDADE PARA A MAIORIDADE - UM DIÁLOGO COM PEDAGOGIA SALESIANA}

Mediante as respostas dadas por Dom Bosco aos problemas da condição juvenil no processo industrial e de toda a transformação social, política, cultural e científica que ocorreu no seu tempo, por meio da pedagogia salesiana como formação integral dos seus jovens, propomos aqui um diálogo com o projeto de uma universidade para a maioridade, como pensou Kant (1724-1804), e a pedagogia salesiana integral projetada por Dom Bosco. Tal propósito tem como finalidade imaginar o papel e o significado da universidade, centro universitário e faculdades católicas na contracultura da mercantilização do ensino. Como discursou Bento XVI aos jovens professores universitários de Madri, em 19 de agosto de 2011: "[...], a universidade encarna um ideal que não deve ser desvirtuado por ideologias fechadas ao diálogo racional, nem por servilismos a uma lógica utilitarista de simples mercado, que olha para o homem como mero consumidor".

Como a proposta da pedagogia salesiana integral de Dom Bosco não é fechada ao diálogo racional e, muito menos, serva da lógica utilitarista e do mercado que reduz o ser humano ao mero consumidor, é, pois, uma educação aberta ao diálogo racional, aos sentidos e à transcendência, ao propor uma formação cristã e cidadã no Estado e na sociedade.

do aluno na sala de aula - como se o aluno fosse um construtor empírico do conhecimento das sensibilidades e das experiências da vida. Voltamos aqui para o tão criticado sistema repressivo (ZIMNIAK, 2013, p. 51). O professor vira apenas um facilitador e motivador (um papagaio das novas metodologias ativas com ares da inovação tecnológica), deixa de ser aquele que ensina e educa, perdendo com isso sua autoridade, como aquele que acrescenta algo na vida dos alunos, para que assim, o aluno torne-se um sujeito com autonomia (um tanto tautológico da nossa parte os dizeres de um sujeito autônomo) e maior como expressou Kant. Sobre a questão da crise da autoridade conferir os ensaios sobre "Que é autoridade?" e a "A Crise da Educação" da Hannah Arendt (ARENDT, 1992). 
Diante da perspectiva de educação integral da pedagogia salesiana na educação para o "bom cristão e o honesto cidadão", podemos promover um diálogo com uma certa distância com a proposta kantiana de esclarecimento na universidade, pois, nos tempos em que vivemos, precisamos recolocar o papel da universidade e da sua identidade nas sociedades contemporâneas. Contudo, se fizéssemos um recuo até o momento histórico que nasce a universidade na idade média entre o século XII - XIII (LE GOFF, 2013, p. 229)ํㅣㄹ. poderíamos perceber que a universidade surge no "seio da Igreja" para responder aos problemas urbanos e a uma nova configuração de mentalidade que se instaurava naquele período, pois, como argumentou Le Goff, "a tomada de consciência dos futuros universitários é apenas um aspecto da tomada de consciência da nova sociedade urbana" LE GOFF, 2013, p. 235). Em síntese, sob o aspecto profissional, a formação nas universidades em seu desenvolvimento em meados do século XII ao XV, como argumentou Le Goff no ensaio sobre "As universidades e os poderes públicos na Idade Média e no Renascimento",

[...], corresponde, com efeito, a um período de crescimento, de especialização e de tecnicização dos ofícios públicos. Vai mesmo até o desenvolvimento das faculdades de medicinas, que corresponde a um esforço maior das autoridades em matéria de salubridade e de saúde pública, com o desenvolvimento do urbanismo e depois da Grande Peste, com a luta contra as epidemias consideradas pelos poderes públicos com um aspecto essencial de sua ação e de seu dever. A procura de saídas profissionais pelos universitários se defronta com a demanda maior dos poderes públicos. (LE GOFF, 2013, p. 259).

Contudo

[...] as universidades, ao se tornarem mais centro de formação profissional a serviço dos Estados do que centro de trabalho intelectual e científico desinteressado, mudavam de função e de fisionomia social. Elas se tornavam menos núcleo de formação de uma intelligentsia original do que um centro de aprendizagem social pelo qual passavam os membros das categorias que formavam a base administrativa e social dos Estados modernos, e, posteriormente, do absolutismo monárquico. Apesar de não ser fácil desvendar o que

\footnotetext{
${ }^{11}$ Sobre esse assunto conferir os estudos e ensaios de Jacques Le Goff sobre a universidade em "Que consciência a universidade teve de si mesma?" e "As universidades e os poderes públicos na Idade Média e no Renascimento" (LE GOFF, 2013). Podemos também consultar o artigo do Roberto Romano (1987) "Lux in Tenebris franciscanos e dominicanos: utopia e democracia (ROMANO, 1987).
} 
é causa ou efeito da mudança de função das universidades nesse fenômeno, é possível [pois, apesar da documentação universitária ser muito mais rica para o Renascimento do que para a Idade Média, falta-nos mais estudos precisos para este último, tendo em vista a fascinação que os períodos das origens exercem nos historiadores] que a origem social dos universitários, em todo caso dos estudantes, tenha se transformado expressivamente no Renascimento, tendo aumentado a proporção dos universitários de origem nobre, o que manifestava ainda a inserção das universidades dentro dos quadros sociais dirigentes da era monárquica. (LE GOFF, 2013, p. 270).

Se as universidades em suas origens e formações respondem aos problemas do seu tempo com postura crítica e não dobrável, como foi no período da Idade Média até o Renascimento, apesar de postura dos poderes eclesiásticos e públicos do Estado em querer enquadrá-las numa perspectiva de ordenamento social e da tradição, como foi o caso da universidade no Renascimento, de certa maneira que se domesticaram os poderes públicos do Estado para atenuarem os seus conflitos.

As universidades que nasciam na Idade Média eram uma tentativa de transcender aos poderes da razão do estado e das classes dominantes, como argumentou Roberto Romano no artigo "Lux e Tenebris franciscanos e dominicanos: utopia democrática". "É admirável notar o quanto esta Ordem, desde sua origem, ligou-se simultaneamente à recriação da igreja, comprometeu-se com os pobres e ajudou a invenção democrática moderna" (ROMANO, 1987, p. 37).

Mas qual é a proposta das nossas universidades, centros universitários e faculdades para os estudantes do nosso tempo? Simplesmente ensiná-los a se adequar e a se sujeitar ao mercado como simples repetidores de determinada forma de conhecimento e saber sem criticidade? Qual será o nosso papel na universidade diante dos problemas sociais, políticos, econômicos, culturais dos nossos tempos?

Vamos partir do pressuposto de que, no nosso tempo, o papel na Universidade - nos centros universitários e nas faculdades diante do momento histórico, político, econômico, social e cultural que vivemos na sociedade brasileira, que é o do capital financeiro, ${ }^{12}$ - é do esclarecimento, pois o esclarecimento é a ousadia de saber, como argumentou Immanuel Kant no opúsculo - Resposta

12 Estudos sobre a situação social, política, cultural e econômica (cf. DOWBOR, 2016a; 2016b; e ROMANO, 2016a; 2016b). 
à pergunta: O que é o Esclarecimento $?^{13}$ (1784). A universidade brasileira passa por um processo de mercantilização dos seus saberes e conhecimento. O ensino universitário virou um produto a ser comercializado na sociedade brasileira com mil e uma propostas metodológicas para motivar o "aluno-cliente"14 e cada vez mais infantilizado e na situação de menoridade ao consumo de novas formas de saber e conhecer, sem nenhuma criticidade. Estamos na contramão da proposta dos iluministas, como Diderot ${ }^{15}$, Condorcet ${ }^{16}$, D' Lambert ${ }^{17}$ e Kant, para citar alguns desses pensadores que podem nos iluminar nesta reflexão sobre a universidade brasileira. Seguindo a tradição iluminista francesa, Kant expressa que o:

Esclarecimento [<Aufklärung>] é a saída do homem de sua menoridade, da qual ele próprio é culpado. A menoridade é a incapacidade de fazer uso de seu entendimento sem a direção de outro indivíduo. O homem é o próprio culpado dessa menoridade se a causa dela não se encontra na falta de entendimento, mas na falta de decisão e coragem de servir-se de si mesmo sem a direção de outrem. Sapere aude! Tem coragem de fazer uso de teu próprio entendimento, tal é o lema do esclarecimento. (KANT, 1783, s.p.).

Observando as universidades, os centros universitários e as faculdades no nosso contexto histórico e social, podemos constatar que o nosso "ensino superior" não está promovendo a proposta kantiana de retirar o indivíduo da condição de menoridade, muito menos desenvolvendo um movimento de esclarecimento que possibilite ao aluno universitário uma atitude de decisão e coragem no uso da razão e do próprio entendimento, pois, como argumentou Roberto Romano no atualíssimo artigo (de 1975) "Democracia e Universidade: interpretação e mundo na Tese XI contra Feuerbach - considerações para uma crítica da prática-prática":

${ }^{13}$ Sobre esse assunto consultar os artigos "Kant e a Aufklärung" (ROMANO, 1985) e "Como a flecha dirigida ao coração do presente. Sobre a preleção de Foucault a respeito do texto de Kant 'O que é Esclarecimento?'” (HABERMAS, 2015).

14 'O campus seria assim como 'o shopping center de bairro', onde alunos buscariam 'mercadorias' - técnicas - adequadas para vencer no campo do trabalho, cada vez mais elitista pela diferença na formação dos indivíduos e grupos" (ROMANO, 2001, p. 42)

15 Para promover a educação superior na Rússia, Diderot (2000) escreve o "Plano de uma Universidade ou de uma educação pública em todas as ciências em 1775" (DIDEROT, 2000).

${ }^{16}$ Sobre esse assunto, ler o texto "Cinco memórias sobre a instrução pública" de Condorcet (2008).

${ }^{17}$ Para ampliar a leitura sobre o assunto recomendamos os livros: "Quatro visões iluminista sobre a educação matemática" (GOMES, (2008) e Ensaio sobre os elementos de filosofia (D' ALAMBERT, 2014). 
Hoje, entre nós, a partir dos mais diversos pontos de vista político e social, a tendência é depreciar a pesquisa fundamental em nome de um critério de compreensão: eficácia prática. Esta é entendida como viabilidade imediata de aplicação do saber e receber prioridade cada vez maior. Decreta-se tranquilamente a falência do pensamento, em nome de um nome de um antiacademicismo apressado e preguiçoso. A reflexão teórica e as instituições que constituem sua base, vistas como distantes e alheias à 'realidade', são negligenciadas. Pouco a pouco elas são relegadas ao destino que lhes reservam o Estado e a produção capitalista: ou dobram-se às injunções do mercado, ou desaparecem. (ROMANO, 1985, 168).

A análise vigorosa, profética e profunda do Roberto Romano é sobre a universidade pública brasileira e a universidade como todo; caso se possa ler o artigo, percebe-se que o autor parte de uma reflexão de Schelling sobre os estudos acadêmicos de 200 anos atrás, mas ela cabe ao ensino superior privado no Brasil, pois o ensino superior privado no Brasil vendeu a sua "alma" ao "mercado"18 e decretou a falência do seu ensino, que é uma atividade pública - todo ensino é público, mesmo numa universidade privada, mas a universidade privada se esqueceu desse pressupostos e, numa atividade de "utilidade mercantil"19 e de extrema eficácia prática e sem a mediação do pensamento e da reflexão ${ }^{20}$, pondera e pesa na balança os processos do conhecimento pro-

\footnotetext{
18 Sobre esse assunto consultar Telmo (2015).

${ }^{19}$ Como discursou Bento XVI (2011) aos jovens professores universitário em Madrid: “..., a universidade foi, e deve continuar sendo, a casa onde se busca a verdade própria da pessoa humana. Por isso, não é uma casualidade que tenha sido precisamente a Igreja quem promoveu a instituição universitária; é que a fé cristã nos fala de Cristo como o Logos por Quem tudo foi feito (cf. Jo 1, 3) e do ser humano criado à imagem e semelhança de Deus. Esta boa nova divisa uma racionalidade em toda a criação e contempla o homem como uma criatura que compartilha e pode chegar a reconhecer esta racionalidade. Deste modo, a universidade encarna um ideal que não deve ser desvirtuado por ideologias fechadas ao diálogo racional, nem por servilismos a um lógica utilitarista de simples mercado, que olha para o homem como mero consumidor.

${ }^{20}$ Essa também era uma preocupação de Bento XVI (2008), isto é: "O perigo do mundo ocidental para falar somente dele é que o homem hoje, precisamente à vista da grandeza do seu saber e do seu poder, desista diante da questão da verdade; significando isto ao mesmo tempo que, no fim de contas, a razão cede face à pressão dos interesses e à atracção da utilidade, obrigada a reconhecê-la como critério derradeiro. Dito do ponto de vista da estrutura da universidade: existe o perigo de que a filosofia, deixando de se sentir à altura da sua autêntica missão, se degrade em positivismo; que a teologia, com a sua mensagem dirigida à razão, seja confinada na esfera privada de um grupo mais ou menos numeroso. Mas, se a razão ciosa da sua presumida pureza se torna
} 
duzido (cf. GIANNOTTI, 2002), refletido e criado se rendeu ao mercado ${ }^{21}$ e aos seus pressuposto de investimentos e $\operatorname{casinos}^{22}$. Quem leciona e habita o ethos da academia - dos saberes e conhecimento universitário e tem o mínimo de sensibilidade, percebe o quanto a gestão universitária se tornou antiacadêmica, apressada, preguiçosa, autoritária (Cf. ROMANO, 2008) e desarticulada nas suas análise e reflexões sobre a finalidade da universidade privada na sociedade brasileira, pois, como argumentou Roberto Romano (2008, p. 169-70), numa universidade:

Preparar o estudante sem torná-lo atento ao todo, é destiná-lo a priori às ações compartimentadas da sociedade civil, do mercado, dos escritórios, das antecâmaras palacianas. É fazer com que ele se resigne aos padrões dominantes que o cercam. Assim, longe de ser anódina, a divisão do saber, levada a cabo em nome da eficácia prática, só conduz a uma atitude inerte e contemplativa frente à política. Entendida como poder administrativo, esta, como as demais esferas da vida, seria própria de especialista, cuja missão precípua é encaminhar e resolver os negócios públicos, cabendo ao filisteu culto obedecer sem questionar.

surda à grande mensagem que lhe chega da fé cristã e da sua sabedoria, seca como uma árvore cujas raízes já não chegam às águas que lhes dão vida. Perde a coragem pela verdade; e deste modo não fica maior, mas menor. Aplicado à nossa cultura europeia, isto significa: se ela quiser autoconstruir-se unicamente com base no círculo das suas próprias argumentações e naquilo que de momento a convence e preocupada com a sua laicidade se separa das raízes de que vive, então não se torna mais razoável nem mais pura, mas desagrega-se e fragmenta-se".

21 "No Brasil, são poucas hoje as instituições universitárias voltadas para o ensino e pesquisa. Essa vinculação é defendida por universidades que não se colocam como finalidade o atendimento às necessidades do mercado ou às estreitas necessidades da sociedade. A forma neoliberal de gerir as políticas de educação superior permitiu que o setor privado no Brasil fosse hoje predominante em termos de ofertas de vagas. A forma de entender o papel e a função da universidade, na análise de Velho (1999, p. 135), faz "as fronteiras entre a universidade e o setor produtivo se fluidificarem na geração da fábrica do conhecimento". É uma visão da universidade como empreendedora e berço de empresas de cunho tecnológico e a lógica da tendência utilitarista da universidade tende a reduzir a construção do conhecimento a mera produção de conhecimento mercadológico" (PEREIRA, 2009, p. 50).

${ }^{22}$ Sobre esse assunto verificar as seguintes indicações: http://www.ihu.unisinos.br/noticias/544698docentes-e-pesquisadores-de-todo-o-mundo-escrevem-carta-a-unesco-reclamando-damercantilizacao-da-educacao\%20; http://www.ihu.unisinos.br/noticias/544548-grandes-gruposeconomicos-estao-ditando-a-formacao-de-jovens-brasileiros-diz-novo-reitor-da-ufrj; http://www. ihuonline.unisinos.br/index.php?option=com_content\&view=article\&id=6596\&secao=492; http:// outraspalavras.net/brasil/para-frear-o-desmonte-das-universidades-publicas./ 
Como podemos constatar pelos argumentos de Roberto Romano, os descaminhos da universidade se constroem paulatinamente na sociedade brasileira, sejam eles nas universidades públicas ou nas universidades privadas, além de se render ao mercado e à eficácia prática, pois hoje as instituições de ensino privada, ao se renderem aos utilitarismos "práticos-da-prática" das eficácias - que são os mecanismos do ensino à distância e das metodologias "inovadoras" ou "ativas", em que o aluno é o protagonista com aulas invertidas - mais parecem colocar o aluno na situação de tutelado e de menoridade, pela incapacidade de as próprias instituições de ensino superior desbravar o tortuoso caminho do conhecimento mediado pela razão e pelos sentidos. E, em nome de uma falta de reflexão pacienciosa, cautelosa, profunda e mediada pela abstração lógica e analítica, boa parte das universidades privadas se rendem à preguiça de ensinar - não querem ensinar os alunos a pensar por conta própria, para dar lugar ao aluno cliente massificado pelo ensino que produz rebanhos e bárbaros ávidos para obedecer às ordens dos donos dos processos mercadológicos, sem questionar e criticar as imposições que os colocam em condições de animais sobreviventes aos limites do mercado. Nesse sentido, podemos concluir que a universidade segue o caminho da tagarelice ${ }^{23}$, e não da investigação e da pesquisa, mas da curiosidade que leva à superficialidade apressada e sem nenhuma mediação reflexiva para o benefício de todos na sociedade (Cf. ROMANO, 2004, p. 205) ${ }^{24}$. Tal perspectiva lança e mergulha a universidade no falatório que expressa a curiosidade que

[...] não se ocupa em ver para entender o visto, isto é, para entrar numa relação de ser com o visto, mas na busca somente de vê-lo. Busca o novo só para saltar novamente desse para outro novo. Não para aprender e, sabendo, estar na verdade, mas busca possibilidades de abandonar-se ao

\footnotetext{
${ }^{23}$ Sobre o assunto, consultar os escritos de Plutarco Sobre a tagarelice (PLUTARCO, 2008). Contudo, parafraseando Plutarco, vale lembrar que será complicadíssima a tarefa de curar a tagarelice da universidade que se rendeu ao mercado, pois, como argumentou Plutarco, "o seu remédio, a palavra, é feito para aqueles que ouvem, e os tagarelas não ouvem ninguém, já que estão sempre falando. Eis o primeiro mal contido na incapacidade de se calar: a incapacidade de ouvir" (PLUTARCO, 2008, p. 11). E, a atual gestão treinada da universidade brasileira no modelo da gestão universitária americana, nada mais é de que uma reprodução tagarela que é incapaz de ouvir os problemas que emergem da sociedade brasileira e contemporânea. Sobre essa questão, conferir o artigo $O$ belo, o verdadeiro, a universidade (ROMANO, 2004). Caso queiram se aprofundar sobre o assunto, verificar a obra Ser e Tempo, parágrafo 35, O falatório (HEIDEGGER, 2012, ).

24 Sobre a diferença entre pesquisa e curiosidade, consultar a nota 22.
} 
mundo. Por isso a curiosidade se caracteriza por uma específica incapacidade de permanecer no imediato. Não busca também o ócio da detenção do sempre novo e a mudança de o-que-vem-de-encontro. Nessa incapacidade de permanecer nas coisas, a curiosidade se ocupa da constante possibilidade de distração. [...] O falatório rege também os caminhos da curiosidade, dizendo: o que a gente deve ter lido e deve ter visto. O ser em toda parte e em parte nenhuma, que caracteriza a curiosidade, está entregue ao falatório. (HEIDEGGER, 2012, p. 485).

Essa incapacidade de "permanecer nas coisas" desvela a nossa falta de profundidade e a busca pelo imediato das informações sem decodificá-las e transformá-la em conhecimento, por causa da nossa ilusão em se inserir, sem criticidade, no processo triturador das engrenagens do mercado que transfigura a vida dos nossos alunos e professores em carvão para serem queimados na máquina do capital. E, num processo de adaptação, acomodação e da impressão de que não existe saída e vida fora do mercado, numa atitude de covardia e preguiça, perpetuamos a condição da universidade sem ciência e de pesquisa da mediocridade. E, com isso, podemos recordar Kant novamente ao situar o nosso alunos e professores na condição que reproduz um modo de ser e "vir a ser", isto é:

A preguiça e a covardia são as causas pelas quais uma tão grande parte dos homens, depois que a natureza de há muito os libertou de uma direção estranha (naturaliter maiorennes), continuem, no entanto de bom grado menores durante toda a vida. São também as causas que explicam por que é tão fácil que os outros se constituam em tutores deles. É tão cômodo ser menor. Se tenho um livro que faz as vezes de meu entendimento, um diretor espiritual que por mim tem consciência, um médico que por mim decide a respeito de minha dieta, etc., então não preciso esforçar-me eu mesmo. Não tenho necessidade de pensar, quando posso simplesmente pagar; outros se encarregarão em meu lugar dos negócios desagradáveis. (KANT, 1783, s.p.).

E continua:

A imensa maioria da humanidade (inclusive todo o belo sexo) considera a passagem à maioridade difícil e além do mais perigosa, porque aqueles tutores de bom grado tomaram a seu cargo a supervisão dela. Depois de terem primeiramente embrutecido seu gado doméstico e preservado cuidadosamente estas tranqüilas criaturas a fim de não ousarem dar um passo fora do carrinho para aprender a andar, no qual as encerraram, mostram-lhes, em seguida, o perigo que as ameaça se tentarem andar sozinhas. Ora, este perigo na verdade não é tão grande, pois aprenderiam muito bem a 
andar finalmente, depois de algumas quedas. Basta um exemplo deste tipo para tornar tímido o indivíduo e atemorizá-lo em geral para não fazer outras tentativas no futuro. É difícil, portanto, para um homem em particular desvencilhar-se da menoridade que para ele se tornou quase uma natureza. Chegou mesmo a criar amor a ela, sendo por ora realmente incapaz de utilizar seu próprio entendimento, porque nunca o deixaram fazer a tentativa de assim proceder. Preceitos e fórmulas, estes instrumentos mecânicos do uso racional, ou, antes, do abuso de seus dons naturais, são os grilhões de uma perpétua menoridade. (KANT, 1783, s.p.).

Em síntese, como argumentou Roberto Romano, a universidade deve viabilizar o conhecimento e o saber técnico, científico e humano, como possibilidades de esclarecimento que disciplina, instrui e educa o cidadão (o jovem) que não se conforma, não fica de joelhos não é preguiçoso e covarde de bom grado diante dos desafios do "mundo da vida", mas é livre e com espírito crítico. Podemos pensar com Kant no escrito "sobre a pedagogia", que indica que a disciplina transforma a animalidade em humanidade, que possibilita uma educação que educa e tira do homem a sua selvageria e o torna o homem observador das leis, pois o homem se torna homem pela educação - "ele é aquilo que a educação faz dele". Nesse sentido, a "educação é uma arte, cuja prática necessita ser aperfeiçoada, por várias gerações" (KANT, 1999, p. 19) ${ }^{25}$ que possibilita ao homem desenvolver as suas disposições para o bem e se educar para a cultura e a ciência, por meio, do esclarecimento que habilita a uma "mentalidade alargada" 26 e o prepara para a vida audaciosa e corajosa consigo mesmo e com os outros no mundo. Este nos parece ser o papel da universidade na atividade do ensino - preparar homens e mulheres para a liberdade fundamentada no esclarecimento da razão e dos sentidos que os lançam no "mundo da vida" para autonomia da dignidade humana.

\footnotetext{
${ }^{25}$ Não temos tempo hábil de tratar do assunto da educação para as gerações, recomendamos o texto Crise na Educação (ARENDT, 1992).

${ }^{26}$ Sobre esse assunto consultar a reflexão de Arendt (1993) sobre Kant em "Lições sobre a filosofia política de Kant".
} 


\section{ENTRE KANT E DOM BOSCO: A PRIMAZIA DA DIGNIDADE HUMANA - TEXTO DE SCHELLING ${ }^{27}$ - LIÇÕES SOBRE O MÉTODO DOS ESTUDOS ACADÊMICOS (1808)}

A educação para a liberdade, a maturidade e a dignidade da pessoa humana pode ser o ponto central entre Kant e Dom Bosco ${ }^{28}$; e que pode ser mediado pelo texto (de mais ou menos uns 200 anos) de Schelling, quando pensamos a universidade:

Quando, no limiar do curso acadêmico, o jovem entra pela primeira vez no mundo das ciências, quanto mais ele sente gosto e pendor pela totalidade, mais diminuem suas oportunidades de ver ali algo que não seja um caos, dentro do qual ele ainda nada distingue, ou um vasto oceano onde se vê jogado sem bússola e sem estrela polar. Não podemos aqui levar em conta o caso excepcional dos raros estudantes a que, em boa hora, uma luz segura indica a via que conduz ao objetivo. A consequência habitual desse estado de coisas é a seguinte: as melhores cabeças entregam-se sem regra ou ordem a todos os estudos possíveis, correm para todas as direções sem nunca chegar ao coração de nenhum problema. Isso, no entanto, é o ponto de partida de uma formação plurilateral e infinita. Nos melhores casos, ainda, saem de seus cursos sem nada dever a seus melhores esforços - infrutíferos-, senão constatar quanta coisa foi feita em vão e quantas coisas essenciais foram negligenciadas; os demais, cuja capacidade de pensamento é menos sólida, resignam-se desde o início, abandonando-se à vulgaridade, e tentam no máximo assimilar sua especialidade particular por uma aplicação mecânica e simples memorização, e isso só enquanto acreditam que tal proceder é indispensável para assegurar seu sustento material no futuro. (SCHELLING apud ROMANO, 1985, p. 168).

\footnotetext{
${ }^{27}$ Aqui reiteramos que seguimos as indicações e reflexões de Roberto Romano (1985) no artigo: "Democracia e universidade. Interpretação e mundo na Tese XI contra Feuerbach - considerações para a crítica da prática-prática". Contudo os erros e os equívocos são nossos, e não do autor indicado e seguido.

${ }^{28}$ Nos Regulamentos Gerais da Sociedade de São Francisco de Sales, no parágrafo 99, encontramos a expressão do esclarecimento kantiano como mote de orientação para os religiosos salesianos, isto é: "A formação requer de cada irmão melhore a capacidade de comunicação e diálogo; que forme uma mentalidade aberta e crítica e desenvolva o espírito de iniciativa para renovar oportunamente o próprio projeto de vida. Cada um cultive o hábito de leitura e do estudo das ciências necessárias à missão; mantenha viva a disponibilidade à oração, meditação, a direção espiritual pessoal e comunitária".
} 
O argumento de Schelling é revelador sobre a formação dos jovens alunos na universidade, pois no início os jovens empolgados, quando adentram o mundo das pesquisas, das investigações e das reflexões, ficam perdidos, outros se apegam às regras sem a práxis da reflexão que ilumina o mundo da vida, e outros tantos se deixam vulgarizar pelo imediato de um suposto saber. Dom Bosco pensava o mesmo sobre os jovens discentes no processo de formação educacional, pois os jovens precisam do educador como mestre e agente que orienta os seus alunos com um itinerário das investigações, dos estudos, das pesquisas e das reflexões dos fundamentos que regem o mundo da vida, e a vida que não se vulgariza pela eficácia prática e imediata (Cf. ZIMNIAK, 2013, p. 50-1).

Não podemos depreciar a pesquisa em nome da eficácia prática e imediata de um suposto saber, pois sabemos que muitos dos alunos entram sem a medida e a noção daquilo que rege a vida acadêmica e, muitas vezes, saem sem o preparo intelectual e crítico que engloba os caminhos e os descaminhos que regem os mecanismos do capital, dos estados e das nossas sociedades, que sustentam o presente e o futuro daquilo que somos e podemos ser. Nesse sentido, como refletiu Roberto Romano sobre a vida acadêmica no Brasil no passado, mas que no atual momento se faz presente, não podemos decretar a falência do pensamento em nome de um antiacademicismo apressado e preguiçoso, não podemos negligenciar o saber universitário mediante a sua reflexão teórica e institucional, muito menos podemos ter uma universidade que se dobre as injunções do mercado, pois, caso isso aconteça, a primazia da dignidade da pessoa humana desaparece, e nós e pouco espaço de tempo também (ROMANO, 1985, p. 168). Sendo assim, "Separar prática e teoria é empobrecedor e tragicômico. Quando intelectuais rejeitam a vida do espírito, merecem, de fato, o riso do poder. Mas isso é expressão de impotência face ao existente. Nada mais" (ROMANO, 1985, p. 166).

A universidade não pode ser mero instrumento de ação de projeto dos interesses imediatos do mercado que esvazia a preocupação com a pesquisa científica e profissional, tal propósito é decretar a morte da universidade. Nesse sentido, parece-nos fundamental pensar, nos 200 anos de Dom Bosco, os valores fundamentais da formação dos nossos jovens para o desenvolvimento das potencialidades que os conduz ao esclarecimento, por meio da técnica, da ciência, das artes, dos sentidos e do pensamento crítico na universidade e para além dos seus muros, pois somente assim a universidade será capaz de responder aos dilemas 
do mundo contemporâneo com iniciativas, propostas e posturas ousadas, arrojadas, corajosas e livres - com isso demostrando para os seus alunos e professores que o medo e o terror não podem ser o parâmetro da vida juvenil da sociedade brasileira e mundial.

\section{CONSIDERAÇÕES FINAIS}

Pensar a figura de Dom Bosco e a sua proposta ousada de educação em um Estado e sociedade em processo de laicização, é um norte para os nossos tempos, pois Dom Bosco não reduziu a sua proposta educacional ao projeto e à tendência secular do "educar-se a si mesmo" que remontava a Grécia antiga (Cf. ZIMNIAK, 2013, p. 52), mas potencializou e desenvolveu um processo educativo que pensou, na prática, a formação do bom cristão e do honesto cidadão. Ter a audácia de Dom Bosco no nosso tempo naquilo que diz respeito à universidade, os centros universitários e faculdades católicas é remar contra a corrente das universidades que se rendem e se reduzem à proposta da mercantilização do ensino que não forma o cidadão para transparência (honestidade da vida pública) e, muito menos, para as transcendências horizontais (lugares possíveis de dignidade) e verticais (O Sagrado) que desvela a vida justa e digna em sociedade.

Enquanto universidade cristã, devemos preservar a nossa identidade cristã católica e ser um sinal profético e crítico no mundo, isto é, com base no diferencial do Sistema Preventivo, devemos encarnar uma proposta de contracultura e resistência livre, dialógica e aberta ao novo, sem se sujeitar ao processo de vulgarização do ensino e aprendizagem que não gera autonomia a homens e mulheres livres como na proposta Kantiana do sapere aude, que funda o pensar, o agir e o fazer no esclarecimento da razão e dos sentidos que promovem a primazia da dignidade da vida no mundo, como foi a vontade de Dom Bosco para os seus jovens.

\section{REFERÊNCIAS}

ARENDT, Hannah. A condição humana. Tradução de Roberto Raposo. Rio de Janeiro: Forense Universitária, 2010.

- Lições sobre a filosofia política de Kant. Tradução de André Duarte de Macedo. Rio de Janeiro: Relumé-Dumará, 1993.

. Entre o passado e o futuro. Tradução de Mauro W. Barbosa de Almeida. São Paulo: Perspectiva, 1992. 
BOSCO, São João. Memórias do Oratório de São Francisco de Sales 1815-1855 (MO). São Paulo: Salesiana, 2005.

BRAIDO, Pietro. Dom Bosco: Padre dos jovens no século da liberdade. Primeiro volume. Tradução Geraldo Lopes e José Antenor Velho. São Paulo: Editora Salesiana, 2008a.

. Dom Bosco: Padre dos jovens no século da liberdade. Segundo volume. Tradução Geraldo Lopes. São Paulo: Editora Salesiana, 2008b.

CONDORCET, Jean-Antoine-Nicolas de Caritat, Marquis de. Cinco memórias sobre a instrução pública. Tradução de Maria das Graças de Souza. São Paulo: Editora Unesp, 2008.

CONSTITUIÇÕES e Regulamentos da Sociedade de São Francisco de Sales. São Paulo: Escolas Profissionais Salesianas, 1984..

D’ ALAMBERT, Jean Le Rond. Ensaio sobre os elementos de filosofia. Tradução de Beatriz Sidou e Denise Bottmann. Campinas, SP: Editora da Unicamp, 2014.

DIDEROT, Denis. Obras I: filosofia e política. Tradução de J. Guinsburg. São Paulo: Perspectiva, 2000.

DOWBOR, Ladislau. Resgatando o potencial financeiro do país. ago. 2016a. Disponível em: <http://dowbor.org/2016/08/ladislau-dowbor-resgatando-o-potencial-financeiro-dopais-versao-atualizada-em-04082016-agosto-2016-47p.html/>. Acesso em: 8 fev. 2017.

. Os irresponsáveis no poder: desmontando o conto da dona de casa. nov. 2016b. Disponível em: <http://dowbor.org/2016/11/dowbor-os-irresponsaveis-no-poderdesmontando-o-conto-da-dona-de-casa-novembro-2016.html/>. Acesso em: 8 fev. 2017.

ENGELS, Friedrich. A situação da classe trabalhadora na Inglaterra. Tradução de B. A. Schumann. São Paulo: Boitempo, 2010.

FERREIRA, Antônio da Silva. Acima e além: os sonhos de Dom Bosco. São Paulo: Salesiana, 2010.

GIANNOTTI, José Arthur. Capitalismo e monopólio do conhecimento. Revista Crítica de Ciências Sociais, Coimbra, Portugal, n. 63, p. 211-35, 2002. Disponível em: <https:// journals.openedition.org/rccs/1283>. Acesso em: 24 fev. 2017.

GOMES, Maria Laura Magalhães. Quatro visões iluminista sobre a educação Matemática. Campinas, SP: Editora Unicamp, 2008.

HABERMAS, Jürgem. A nova obscuridade. Tradução de Luiz Repa. São Paulo: Editora da Unesp, 2015.

HEIDEGGER, Martin. Ser e tempo. Tradução de Fausto Castilho. Campinas, SP: Editora da Unicamp; Petrópolis, RJ: Vozes, 2012.

KANT, Immanuel. Sobre a pedagogia. Tradução de Francisco Cock Fontanella. Piracicaba, SP: Editora Unimep, 1999. 
200 anos de Dom Bosco: a Pedagogia Salesiana, a Universidade para a Maioridade e a Primazia da Dignidade da Pessoa Humana

. Resposta à pergunta o que é o esclarecimento? 1783. Tradução de Luiz Paulo Rouanet. Disponível em: <http://bioetica.catedraunesco.unb.br/wp-content/ uploads/2016/04/Immanuel-Kant.-O-que-\%C3\%A9-esclarecimento.pdf>. Acesso em: 28 mar. 2017.

LE GOFF, Jacque. Para uma outra Idade Média: tempo, trabalho e cultura ocidental. Petrópolis, RJ: Vozes, 2013.

MARX, Karl; ENGELS, Friedrich. Manifesto comunista. Tradução de Álvaro Pina e Ivana Jinkings. São Paulo: Boitempo, 2010.

MARX, Karl. O capital: crítica da economia política: Livro I: o processo de produção do capital. Tradução de Rubens Enderle. São Paulo: Boitempo, 2013.

PAPA BENTO XVI. Discurso por ocasião da XXVI Jornada Mundial Da Juventude. 19 ago. 2011. Disponível em: <https://w2.vatican.va/content/benedict-xvi/pt/speeches/2011/ august/documents/hf_ben-xvi_spe_20110819_docenti-el-escorial.html>. Acesso em: 5 mar. 2017.

PAPA BENTO XVI. Discurso do Santo Padre Bento XVI para o Encontro na Universidade de Roma "La Sapienza". 2008. Disponível em: <https://w2.vatican.va/content/benedict-xvi/ pt/speeches/2008/january/documents/hf_ben-xvi_spe_20080117_la-sapienza.html>. Acesso em: 4 mar. 2017.

PAPA FRANCISCO. Carta ao Bicentenário de Dom Bosco. 2015. Disponível em: <http:// www.boletimsalesiano.org.br/index.php/noticias-bs/item/4982-papa-francisco-enviacarta-ao-reitor-mor-dos-salesianos-pelo-bicentenario>. Acesso em: 1o mar. 2017.

PEREIRA, Elisabete Monteiro de Aguiar. A universidade da modernidade nos tempos atuais. Avaliação, Campinas/Sorocaba, SP, v. 14, n. 1, p. 29-52, mar. 2009. Disponível em: $<$ http://www.scielo.br/scielo.php?script=sci_arttext\&pid=\$1414-40772009000100003\&ln $\mathrm{g}=$ pt\&nrm=iso $>$. Acesso em: 24 fev. 2017.

PINO, Angel. Ciência e educação: a propósito do bicentenário do nascimento de Charles Darwin. Educação \& Sociedade, Campinas, SP, v. 30, n. 108, p. 845-66, out. 2009 . Disponível em: <http://www.scielo.br/scielo.php?script=sci_arttext\&pid=S010173302009000300011\&lng=pt\&nrm=iso>. Acesso em: 26 mar. 2017. http://dx.doi. org/10.1590/S0101-73302009000300011.

PLUTARCO. Sobre a tagarelice e outros textos: seguido de sobre a demora da justiça divina e das doenças da alma e do corpo. Tradução de Mariana Echalar. São Paulo: Landy, 2008.

ROMANO, Roberto. Depois das ditaduras ferozes, sobrou a miragem democrática. Revista do Instituto Humanitas Unisinos, ed. 493, set. 2016a. Disponível em: <http:// www.ihuonline.unisinos.br/index.php?option $=$ com_content $\& v i e w=$ article\&id $=6623 \& \mathrm{~s}$ ecao=493>. Acesso em: 8 fev. 2017. 
. O MP é apenas um fármaco. A superconcentração do Executivo é a causa da corrupção. Entrevista especial com Roberto Romano. Revista do Instituto Humanitas Unisinos, set. 2016b. Disponível em: <http://www.ihu.unisinos.br/159-entrevistas/560651a-superconcentracao-do-executivo-e-a-causa-da-corrupcao-e-o-mp-e-apenas-umfarmaco-entrevista-especial-com-roberto-romano>. Acesso em: 8 fev. 2017.

. Gestão universitária, autonomia, autoritarismo. Revista USP, São Paulo, n.78, p. 48-57, jun./ago. 2008. Disponível em: <https://www.revistas.usp.br/revusp/article/ view/13677/15495>. Acesso em: 8 fev. 2017.

. O desafio do Is/ã e outros desafios. São Paulo: Perspectiva, 2004.

. Caldeirão de média. São Paulo: Perspectiva, 2001.

. Lux In Tenebris: meditações sobre filosofia e cultura. Campinas, SP: Editora Unicamp; Cortez, 1987.

. Corpo e cristal: Marx romântico. Rio de Janeiro: Editora Guanabara, 1985.

ROUSSEAU. Jean-Jacques. Emílio ou, da educação. 3. ed. Tradução de Roberto Leal Ferreira. São Paulo: Martins Fontes, 2004.

TELMO, Marcos. Declaração de Bolonha no contexto de mercantilização da educação superior: o discurso neoliberal dos organismos multilaterais. Espaço Pedagógico, Passo Fundo, RS, v. 22, n. 2, p. 264-86, jul./dez. 2015. Disponível em: <http://seer.upf.br/index. php/rep/article/view/5570>. Acesso em: 25 fev. 2017.

ZIMNIAK, Stanislaw. O sistema educativo de São Bosco. O contexto de formação e seus fundamentos em relação ao educador. Cadernos Salesianos - Nova série, São Paulo, v. 7, semestral, 2013.

\section{Sobre os autores:}

Daner Hornich: Doutorado em filosofia pela Pontifícia Universidade Católica de São Paulo. Mestrado em Filosofia pela Pontifícia Universidade Católica de São Paulo. Graduado em Filosofia. Atualmente é professor do Centro Universitário Salesiano de São Paulo. E-mail: danerhornich@hotmail.com

Fabio Camilo Biscalchin: Doutorando pela UPS (Roma) em Educação. Mestre em Educação (Filosofia) pela Universidade Metodista de Piracicaba. Graduado em Filosofia pelo Centro Universitário Salesiano de São Paulo. Professor em regime parcial no Centro Universitário Salesiano de São Paulo - Unidade Americana.

E-mail: fabiocamilo@uol.com.br

\section{Recebido em dezembro de 2017}

\section{Aprovado em março de 2018}

